European Association for the Development of Renewable Energies,

Environment and Power Quality (EA4EPQ)
International Conference on Renewable Energies and Power Quality

(ICREPQ'11)

Las Palmas de Gran Canaria (Spain), 13rd to 15th April, 2011

\title{
A comparison of transformer HF models and their application to PQ analysis
}

\author{
Department of Electrical Engineering \\ E.T.S.I.I.T. University of Cantabria \\ Avda. Los Castros s/n \\ 39005 Santander, Cantabria \\ Spain
}

C. Capellán, M. Mañana, A. Arroyo, L.M. Muñiz and F. Delgado

Phone: +34942201378 Fax: +34942201385 Email: mananam@unican.es

\begin{abstract}
This research work is devoted to the comparison of some proposed high-frequency (HF) models of transformers and their application to power quality (PQ) studies. The models are classified according their structure, physical description and experimental methodology and set-up facilities needed to obtain the parameters.
\end{abstract}

\section{INTRODUCTION}

High-frequency modeling is essential during the design stage of power transformers in order to study the impulse voltage response, the winding integrity, power quality problems and also for insulation diagnosis. In some cases, high-fidelity models in a bandwidth up to $10 \mathrm{MHz}$ are required for condition monitoring purposes.

From an experimental point of view the study of the high-frequency part of the spectra have to be done in order to obtain the stray capacitances that shunt the series inductances and dominating the response.

\section{HF MODELS}

\section{A. Physics-based models}

This type of model is close to the real behavior of the real transformer [1-3]. The main drawback of this approach is the neccessity of information about the physical structure of the machine, including dimensions, materials and geometry. The needed data is raraley provided by the transformer manufacturer. Fig 1 shows a finite elements model using the physical description of the machine.

\section{B. Black-box models}

Black-box models are suitable to obtain the HF behavior of the transformer when it is difficult to obtain information about the machine. The basic idea is to obtain the transfer function using transient information about

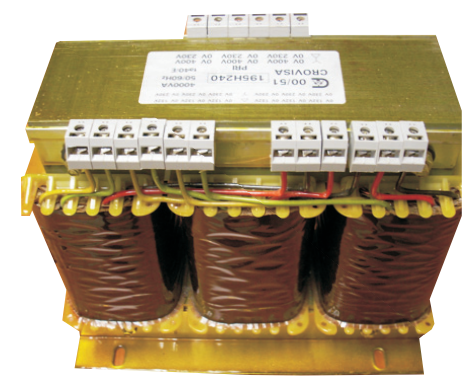

(a)

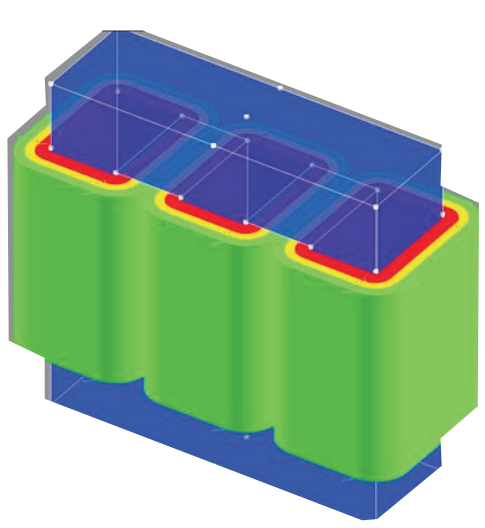

(b)

Figure 1. Finite elements description of a laboratory transformer. (a) Image of the real transformer; (b) Finite Elements model.

voltage and current [4]. The admittance matrix is defined in the frequency domain in ranges that goes from $50 \mathrm{~Hz}$ to $1 \mathrm{MHz}$. Numerical models are introduced based on 
two-port network theory [5-8] where its parameters are computed at different resonance frequencies which are experimentally measured.

The advantage of this approach regarding physical models is their ability to work with commercial grade transformers. Fig. 2 shows a two-port description of a single fase transformer for HF modeling.

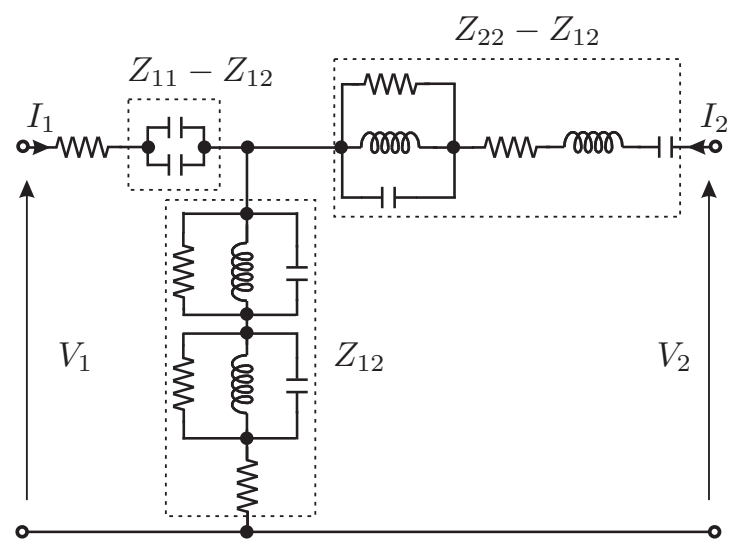

Figure 2. HF two-port description of a laboratory transformer [5].

\section{MODEL COMPARISON}

Model comparative has been made by introducing a set of basic parameters related with three key points:

Model The type of model from the point of view of their physical meaning. There are two main sets: i) Physical. The parameters of the model have a physical equivalent and ii) Black-box. The parameters are computed using a mathematical approach without considering their physical meaning.

Frequency The range of frequency in which the model is accurate enough. The frequency spectrum is partitioned in three bands: i) dc $2.5 \mathrm{kHz}$; ii) $2.5 \mathrm{kHz}-1 \mathrm{MHz}$ and iii) 1 $\mathrm{MHz}$ to $\infty$.

Data The theoretical or experimental approach followed to obtain the parameters: i) Nameplate data; ii) Experimental high-frequency (HF) data; iii) Experimental low-frequency (LF) data and iv) Finite elements software.

Table I summarizes a comparison between models according to different criteria. The comparison includes information about the data source, the type of model used and the experimental approach needed for parameter extraction.

\section{PQ REQUIREMENTS}

The standard IEEE Std. 1159 [9] provides a detailed description of each disturbance in terms of their typical spectral content, duration and magnitude. The summary provided by table II can be used as a reference point in order to define the models in terms of frequency spectrum and amplitude. The amplitude is also important because the saturation problem. At low frequencies (between 50$60 \mathrm{~Hz}$ and $3 \mathrm{kHz}$ ) it is expected that classic models could be extended to consider harmonic losses and additional saturation.

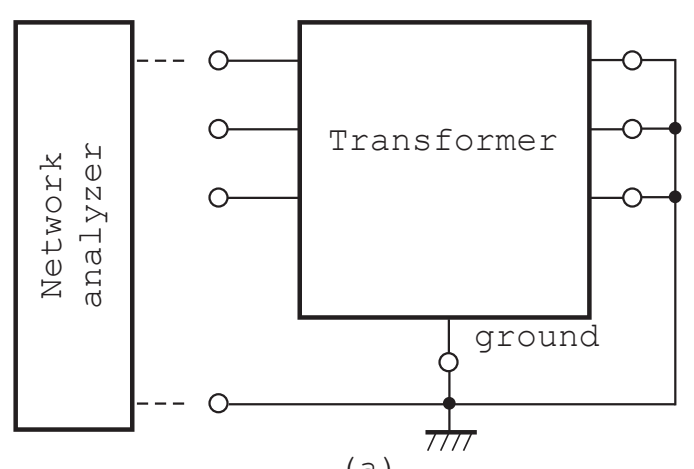

(a)

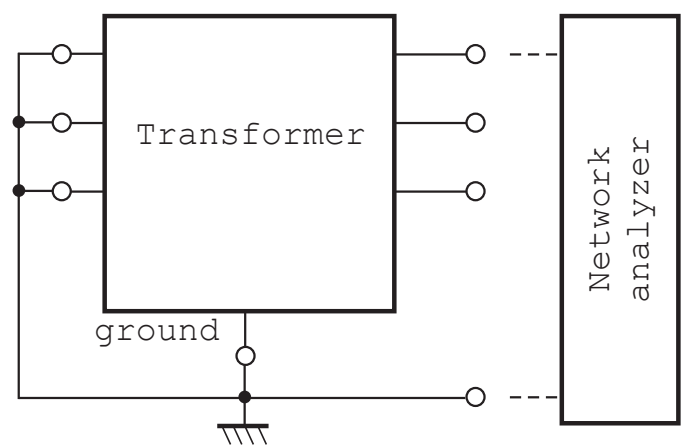

(b)

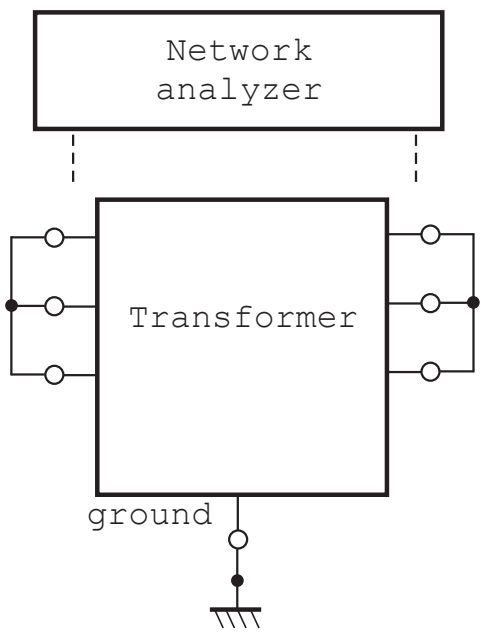

(c)

Figure 3. Transformer connection for the capacitance measurement. 
TABLE I

COMPARISON BETWEEN DIFFERENT TRANSFORMER HF MODELS.

\begin{tabular}{|l|l|c|c|c|c|c|}
\cline { 3 - 6 } \multicolumn{2}{c|}{} & \multicolumn{5}{c|}{ Model } \\
\hline & Abed [1] & Sabiha [5] & Gustavsen [4] & Zhongyuan [7] & Abeywickrama [3] \\
\hline \multirow{3}{*}{ Model } & Physical & $\checkmark$ & & & & $\checkmark$ \\
\hline & Black-box & & $\checkmark$ & $\checkmark$ & $\checkmark$ & \\
\hline \multirow{5}{*}{ Frequency } & $f \leq 2.5 \mathrm{kHz}$ & & & & & \\
\hline & $2.5 \mathrm{kHz}<f \leq 1 \mathrm{MHz}$ & $\checkmark$ & & $\checkmark$ & & $\checkmark$ \\
\hline & $f>1 \mathrm{MHz}$ & & $\checkmark$ & & $\checkmark$ & \\
\hline \multirow{5}{*}{ Data } & Nameplate & & & & & \\
\hline & Experimental HF & & $\checkmark$ & $\checkmark$ & $\checkmark$ & \\
\hline & Experimental LF & & & & & \\
\hline & Finite elements & $\checkmark$ & & & & $\checkmark$ \\
\hline
\end{tabular}

TABLE II

CATEGORIES AND TYPICAL CHARACTERISTICS OF POWER SYSTEM ELECTROMAGNETIC PHENOMENA AS DEFINED IN IEEE STD. 1159 [9] VS SIMULATION MODEL.

\begin{tabular}{|l|l|l|l|l|}
\hline Categories & $\begin{array}{l}\text { Typical spectral } \\
\text { content }\end{array}$ & Typical duration & $\begin{array}{l}\text { Typical voltage } \\
\text { magnitude }\end{array}$ & model \\
\hline 1.0 Transients & $\begin{array}{l}5 \mathrm{~ns} \mathrm{rise} 0.55 \\
\mathrm{MHz}\end{array}$ & $<50 \mathrm{~ns}$ & $08 \mathrm{pu}$ & $\begin{array}{l}\text { Sabiha [5] } \\
\text { Zhongyuan [7] }\end{array}$ \\
\hline $\begin{array}{l}\text { 2.0 Short-duration root-mean-square (rms) vari- } \\
\text { ations }\end{array}$ & & $\begin{array}{l}\text { Between } 0.5 \mathrm{cy}- \\
\text { cles and } 1 \mathrm{~min}\end{array}$ & $0.1-1.8 \mathrm{pu}$ & Classic models \\
\hline 3.0 Long duration rms variations & $>1 \mathrm{~min}$ & $0-1.2 \mathrm{pu}$ & Classic models \\
\hline 4.0 Imbalance & & steady state & $0.5-30 \%$ & Classic models \\
\hline 5.0 Waveform distortion & $09 \mathrm{kHz}$ and & steady state & $0-20 \%$ & $\begin{array}{l}\text { Abed [1], Gustavsen } \\
\text { and Abeywick- } \\
\text { ama [3] }\end{array}$ \\
\hline 6roadband Voltage fluctuations & $<25 \mathrm{~Hz}$ & intermittent & $0.1-7 \%$ & Classic models \\
\hline 7.0 Power frequency variations & & $<10 \mathrm{~s}$ & $\pm 0.10 \mathrm{~Hz}$ & Classic models \\
\hline
\end{tabular}

\section{SET-UP}

The set-up facility allows us to obtain the parameters of the model. It is necessary to carry out three different sets of measurements:

1) open-circuit.

2) short-circuit.

3) capacitance measurement.

The connections used for open-circuit and short-circuit follow the classical approach that is used at nominal frequency $(50$ or $60 \mathrm{~Hz}$ ). For the measurement of capacitances it has been proposed three configurations [10]. Fig. 3 summarizes the three configuration needed for the capacitance measurements:

- Input capacitance. Fig. 3.a shows the configuration for the measurement of the input capacitance.

- Output capacitance. Fig. 3.b shows the configuration for the measurement of the output capacitance.

- I-O capacitance. Fig. 3.c shows the configuration for the measurement of the input to output capacitance.

\section{COnClusions}

This research work establishes a comparison between different models that can be used for high-frequency modeling. The comparison includes different criteria like the type of model and the experimental methodology and set-up. In a future work the models will be evaluated in a experimental way in order to compare their accuracy.

\section{References}

[1] N. Abed and O. Mohammed, "Physics-based high-frequency transformer modeling by finite elements," Magnetics, IEEE Transactions on, vol. 46, no. 8, pp. 3249 -3252, 2010.

[2] O. Mohammed and N. Abed, "Application of finite elements to high frequency transformer modeling," Electromagnetic Field Computation, 2006 12th Biennial IEEE Conference on, pp. 100 100, 2006.

[3] N. Abeywickrama, Y. Serdyuk, and S. Gubanski, "High-frequency modeling of power transformers for use in frequency response analysis (fra)," Power Delivery, IEEE Transactions on, vol. 23, no. 4, pp. 2042 - 2049, 2008.

[4] B. Gustavsen, "Wide band modeling of power transformers," Power Delivery, IEEE Transactions on, vol. 19, no. 1, pp. 414 $-422,2004$ 
[5] N. Sabiha and M. Lehtonen, "Lightning-induced overvoltages transmitted over distribution transformer with mv spark-gap operation;part i: High-frequency transformer model," Power Delivery, IEEE Transactions on, vol. 25, no. 4, pp. 2472 -2480, 2010.

[6] A. Morched, L. Marti, and J. Ottevangers, "A high frequency transformer model for the emtp," Power Delivery, IEEE Transactions on, vol. 8, no. 3, pp. 1615 -1626, July 1993.

[7] Z. Zhongyuan, L. Fangcheng, and L. Guishu, "A high-frequency circuit model of a potential transformer for the very fast transient simulation in gis," Power Delivery, IEEE Transactions on, vol. 23, no. 4, pp. 1995 - 1999, 2008.

[8] Z. Zhongyuan, C. Yutong, L. Yupeng, and L. Fangcheng, "High frequency circuit model of transformer windings based on frequency responses for vfto studies," Electric Utility Deregulation and Restructuring and Power Technologies, 2008. DRPT 2008. Third International Conference on, pp. 1528 - 1532, 2008.

[9] "Ieee recommended practice for monitoring electric power quality," IEEE Std 1159-2009 (Revision of IEEE Std 1159-1995), pp. c1 -81, 262009

[10] T. Tran-Anh, P. Auriol, and T. Tran-Quoc, "High frequency power transformer modeling for power line communication applications," in Power Systems Conference and Exposition, 2006. PSCE 'O6. 2006 IEEE PES, 292006. 